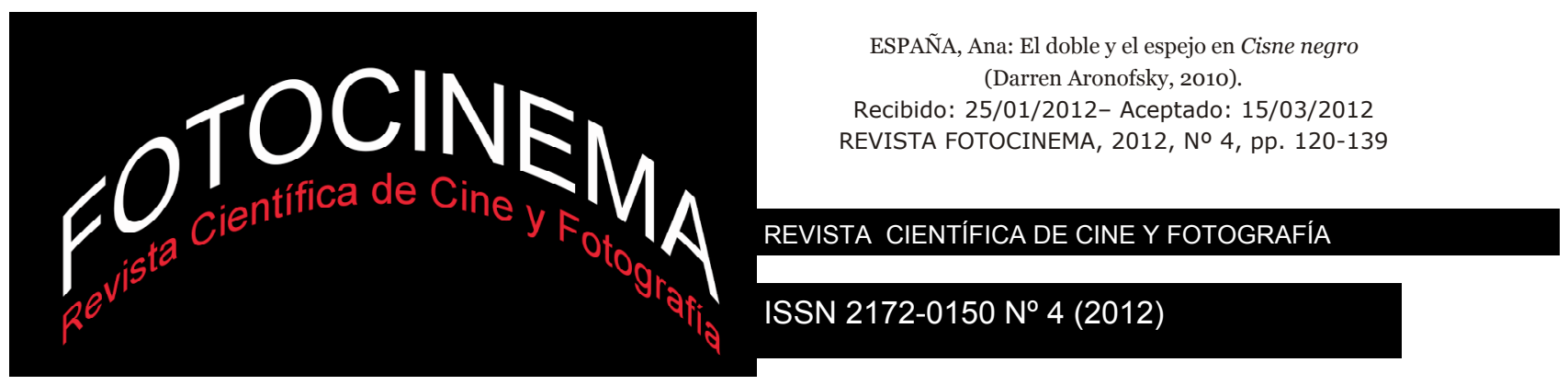

\title{
EL DOBLE Y EL ESPEJO EN CISNE NEGRO \\ (DARREN ARONOFSKY, 2010)
}

\section{THE DOUBLE AND THE MIRROR IN BLACK SWAN (DARREN ARONOFSKY, 2010)}

\section{Resumen:}

Con su último largometraje, Cisne negro (2010), Darren Aronofsky propone una nueva visión de su cine de la obsesión, a través del proceso de autodestrucción de una bailarina, sumergida en su afán por encarnar el papel principal en una obra de ballet.

El presente artículo trata de abordar el tratamiento que el director realiza del fenómeno del doble, como vehículo sobre el que se sustenta la crisis obsesiva de la protagonista, atendiendo a sus diversas representaciones y objetivos en la configuración final del texto.
Ana España

Universidad de Málaga

\begin{abstract}
:
With his latest film, Black Swan (2010), Darren Aronofsky offers a new vision of his obsession cinema, through the process of selfdestruction of a dancer, immersed in her effort to embody the lead role in a ballet performance.

This current article aim to attend the director treatment of the double phenomenon as a vehicle on which rests the obsessive crisis of the protagonist, according to their several representations and objectives in the final configuration of the text.
\end{abstract}

\section{Palabras clave:}

Obsesión, Aronofsky, Doble, Espejo, Blanco-Negro.

\section{Key words:}

Obsession, Aronofsky, Double, Mirror, White-Black. 


\section{Introducción}

En la época de la posmodernidad, en la que el cuerpo se ha configurado como una expresión del vacío, malestar o ausencia, Aronofsky nos propone en su última película la mostración de un cuerpo que se mira en el espejo. En este sentido, el relato nos conduce por el camino clásico de la psicología que transitaron Freud y Lacan, y que enlaza con la represión, las obsesiones y el doble como expresión del yo. En Cisne negro se conjuga un relato que se sustenta en El lago de los cisnes y El doble de Dostoievski. Simultáneamente hay un conjunto de referencias - las más de las veces cinematográficas- con las figuras centrales de Cronenberg y Polanski, que nos llevan a la transformación y manipulación del cuerpo con su consiguiente cambio de la identidad. Por otro lado, el cuerpo se visualiza como un extraño, como otro yo en el que la protagonista se mira entre la repulsión, la enajenación y una cierta fascinación.

La diferencia entre un avatar, cuyo cuerpo se proyecta en otro, es que aquí se trata de reconocerse en el propio. En este sentido, Aronofsky se muestra más moderno que posmoderno, pues el cuerpo no deja de ser el combate en el que se dan cita las pasiones, los sentimientos y el principal medio de expresión.

\section{Cisne blanco - Cisne negro}

“Todos conocemos la historia. Pequeña niña virgen, pura y dulce, atrapada en el cuerpo de un cisne. Ella desea la libertad, pero solo el amor verdadero romperá el hechizo. Su deseo es casi concedido en la forma de un príncipe. Pero antes de que él le pueda declarar su amor, su gemela lujuriosa, el cisne negro, lo engaña y seduce. Devastada, el cisne blanco se arroja desde un acantilado, matándose. Y en la muerte, halla la libertad".

Con este breve discurso introductorio, Thomas Leroy (Vincent Cassel), el director de la compañía de ballet, señala la primera manifestación del fenómeno del doble en Cisne negro, -ubicada en una reformada versión de El Lago de los cisnes- y la traslada al propio discurso narrativo del film: "Pero, ¿cuál de vosotras puede encarnar a ambos cisnes? El blanco y el negro”.

Bajo esta pregunta clave se sostiene el rasgo que mejor caracteriza y define a Cisne negro: la dualidad como el eje central que vertebra todo el film, 
materializado en el doble papel de la obra de ballet al que se enfrenta Nina (Natalie Portman), la bailarina protagonista del relato.

$\mathrm{Su}$ apariencia frágil, pura y virginal la convierten en la mejor opción para complacer las demandas que exige el rol del cisne blanco. Sin embargo, es incapaz de transmitir los requisitos indispensables -la sensualidad, la seducción y el erotismo- para representar a su malvada gemela rival, el cisne negro.

Esta imposibilidad de compatibilizar ambos estados será reafirmada por Leroy cuando, tras fracasar en las audiciones para optar al papel, Nina acude a su despacho, en la búsqueda de una nueva oportunidad:

"La verdad es que cuando te miro, veo al cisne blanco. Sí, eres hermosa, temerosa, frágil. Eres perfecta para ese papel. Pero, ¿el cisne negro? Es muy difícil representar a ambos”. Cuando Nina garantiza, convencida, su capacidad para interpretar al cisne negro, el director acaba por subrayar: "Cada vez que bailas, noto una obsesión por hacer que cada movimiento sea absolutamente perfecto, pero nunca te vi dejarte llevar. Nunca. ¿Para qué tanta disciplina?”.

El fenómeno de la obsesión es transmitido en boca de uno de los personajes, como proyección del mecanismo por el que se rige la conducta de la protagonista. Un estado que nos traslada al resto de películas que componen la filmografía de Aronofsky. Nando Salvá destaca en una reseña al director que:

“Todas ellas hablan de la obsesión, de personas que, por las cosas que aman, llegan a extremos irracionales y con frecuencia a la autodestrucción” (Salvá, 2011: 52).

En efecto, los personajes que habitan sus relatos, están movidos por una determinada obsesión. Desde el empeño del excéntrico matemático de $P i$, fe en el caos (Faith in Chaos, 1998), por descubrir el significado oculto de un patrón numérico, hasta La fuente de la vida (The Fountain, 2006), con la incesante lucha del protagonista por hallar la cura contra el cáncer, que salve a su esposa de la muerte. En Cisne negro, por otro lado, Nina es la encargada finalmente de, tras las recriminaciones de Leroy, revelar el sentido de su particular obsesión: "Solo quiero ser perfecta".

Esta perfección como forma de obsesión, se edifica en torno a la obtención del papel protagonista en la obra de ballet, y junto a ello, el título de primera 
bailarina en la compañía. Un estado perpetuado hasta entonces en la figura de Beth (Winona Ryder), imagen venerada por Nina, expulsada y pendiente de ser reemplazada.

De modo que esta obsesión se va a regir, al igual que en los largometrajes anteriores del director, a través de la conducta de la protagonista, donde su incapacidad para ejecutar el doble rol la conducen hasta una crisis psicótica que deriva en un posterior desdoblamiento de personalidad. Momento que encuentra su total consolidación cuando Leroy, tras la conversación en su despacho, decide concederle el papel principal.

La dualidad omnipresente en todo el relato, se pondrá de manifiesto desde el arranque del film, y a través de la presencia de los dos colores tradicionalmente antagónicos, unidos bajo los títulos de créditos: el blanco y el negro que dan nombre a las dos entidades protagonistas en la famosa obra de ballet y que actúan como representación, a su vez, de las dos subjetividades contrarias que convergen en la mente de Nina. Explotados bajo el concepto del ying-yang, el negro-blanco invade cada espacio, ambiente o personaje implicado en el desarrollo de la diégesis.

En el inicio del relato, los colores claros (blanco y rosa) son los que subrayan la realidad infantiloide por la que discurre Nina, emplazados en un dormitorio poblado por animales de peluche y claros representantes de su vestuario. Un exaltado estado de niñez permanente que acentúa la presencia invisible del cisne blanco.

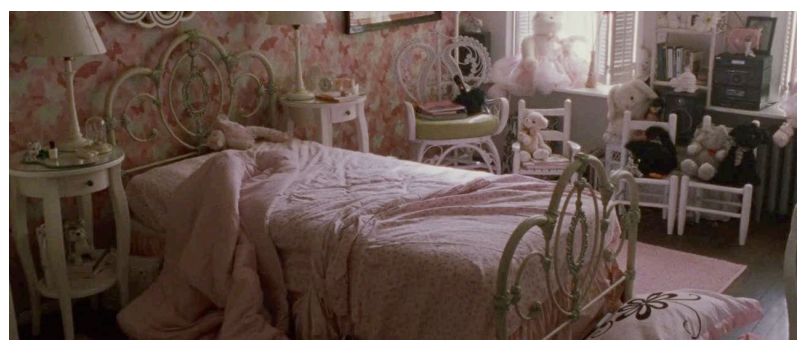

A medida que su mente comienza a distorsionarse, a raíz de su enfermiza implicación en el rol del cisne negro, la atmósfera que la rodea se descompone a su vez. Desde su vestuario, cuyas ropas adquieren tonalidades grisáceas y negras que nos trasladan al cisne malvado, hasta los diferentes ambientes que enfatizan los estados alucinatorios que la conducen a la crisis psicótica. 
Cisne negro se construye, por lo tanto, bajo la presencia de dos estados o fuerzas interiores que permanecen en una constante lucha en la mente trastornada de la protagonista (la imagen virginal que transmite y la búsqueda de la liberación a la que aspira) y de cuya resolución se establece el posterior devenir del relato.

Este tipo de estructura psicótica, instaurada en torno al fenómeno del doble, se manifiesta a través de dos encarnaciones que se alimentarán mutuamente entre sí a lo largo del film, y en cuyo tratamiento y función concreta en el desarrollo de la narración nos centraremos a continuación.

\section{El fenómeno del doppelgänger o el gemelo malvado}

Nina camina frustrada hacia su casa tras el estrepitoso fracaso en las audiciones al puesto de primera bailarina para la obra de ballet. Al llegar a la entrada de un estrecho y lúgubre callejón, se percata de la presencia de una figura femenina, situada al otro lado y que la observa en la oscuridad. Acto seguido, comienza a andar apresuradamente en dirección a Nina, que es impulsada, automáticamente, a reanudar su camino y afrontar el encuentro inevitable entre ambas.

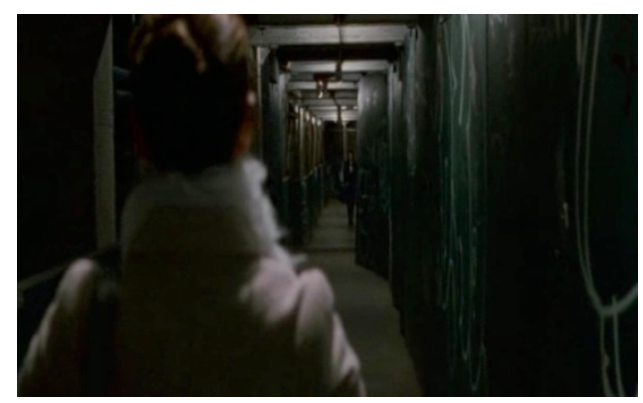

En este momento, el montaje se configura en torno a la alternancia de dos planos concretos -subjetivos desde Nina y los respectivos planos de réplica de su rostro desconcertado-, que subraya y prolonga en el tiempo la tensión que preside la escena, y que se ve incrementada por el sonido de sus pisadas, enfatizadas por la banda sonora. Al producirse el choque entre ambos personajes, la cámara vuelve, como definiría José A. Navarro (2011: 26), al subjetivismo descriptivo al que tiene habituado al espectador desde el inicio del relato. De este modo, se ilustra la primera de una larga serie de manifestaciones del doble -del rostro de la propia Nina- inserto, esta vez, sobre el rostro de la 
desconocida transeúnte. Una breve aparición que será acentuada con una pequeña carcajada femenina, que emergerá, a partir de este fragmento, cada vez que el doble obtiene protagonismo. Automáticamente, la imagen es reemplazada por el rostro original de la joven, como parte intrínseca de la fase alucinatoria.

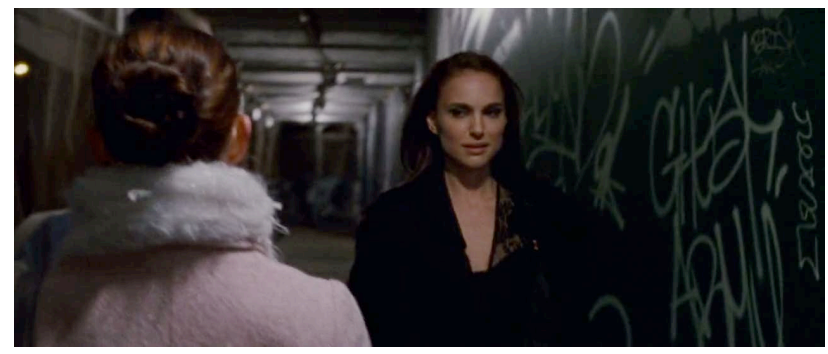

El encuadre bajo el que se configura la confluencia entre ambos personajes viene determinada por la presencia de los dos colores opuestos y su evocación a las dos aves protagonistas. El blanco/rosa de Nina enfrentado al negro del doble. Los dos lados -la luz y la oscuridad- de una misma imagen.

De este fragmento de cierto carácter onírico, se deriva la llegada e instauración de la psicosis en la mente de Nina, representada a través de su cruce con el doble, como vía a la sustitución mental, al nacimiento del desdoblamiento.

Ya en el clásico film de Polanski, Repulsión (1965), fue trabajado este estado de proyección, en el que el personaje protagonista es víctima de un desdoblamiento ante la inesperada pérdida de la protección fraternal, quedando a merced de sus delirios psicóticos. En ambos textos, las dos jóvenes se ven desprovistas de los registros simbólicos necesarios para enfrentar una situación que les lleva a desvincularse de la realidad. La irrupción de la sexualidad se erige como premisa principal, establecida en Cisne negro mediante los rasgos asociados al personaje de la obra de ballet, y en Repulsión, a través de la relación sentimental que provoca la destrucción del vínculo con su hermana, así como de los pretendientes que la abordan durante su aislamiento. La imagen del doble encarna el factor inexistente en ambas (lo sexual) duplicado y exteriorizado, acompañado de connotaciones negativas o, como lo denominaba Freud, con un carácter siniestro o unheimlich:

"Unheimlich, es todo lo que estando destinado a permanecer en secreto, en lo oculto, ha salido a la luz" (Freud, 1992: 225). 
Este proceso de expulsión del doble, representado en la escena anterior, nos conduce hasta la obra de Dostoievski, El doble, a la cual Aronofsky alude como base central sobre la que sustenta todo el discurso:

"A veinte pasos de él se perfiló la figura de un hombre que se le acercaba apresuradamente, a un buen trote, acortando veloz la distancia que mediaba entre ellos [...] El señor Goliadkin pudo al fin ver con calidad a su nuevo compañero noctámbulo y lanzó una exclamación de asombro y horror [...] Su amigo nocturno no era otro que él mismo, el propio señor Goliadkin, otro señor Goliadkin, pero absolutamente idéntico a él...en una palabra, su doble" (Dostoievski, 1985: 26-27).

De la traslación de esta escena de la obra de Dostoievksi, deriva la definitiva consolidación del doble, a través del encontronazo del sujeto principal con la visión duplicada de sí mismo. De la estrecha relación entre ambos textos, Aronofsky declararía:

"Ya estaba pensando en hacer una adaptación de El Doble de Dostoievski, que trata sobre un hombre que un día despierta y se encuentra con que otro hombre ha comenzado a ocupar lentamente el mismo lugar que él en su vida. Luego vi El lago de los cisnes y me di cuenta de que el tema era muy similar. La misma bailarina hace del Cisne blanco y del cisne negro. $\mathrm{Y}$ es incluso mejor que $E l$ doble porque aquí son dos personajes completamente diferentes" (Aronofsky, 2011: 30).

Esta pequeña variación, ya apuntada por el director, se convierte en el aspecto diferenciador por el que se configura Cisne negro. La identificación de Nina con una figura contraria, bajo la cual se lleva a cabo el desdoblamiento o, volviendo a palabras de Freud:

"La identificación con otra persona hasta el punto de equivocarse sobre el propio yo o situar el yo ajeno en el lugar del propio - o sea, duplicación, división, permutación del yo-“ (Freud, 1992: 234).

En este caso, cobra una especial importancia la figura de Lily (Mila Kunis), la nueva bailarina que llega a la compañía para llevar a cabo una sustitución y acaba convirtiéndose en una de las candidatas a optar al puesto de primera bailarina. Su interés radica en manifestarse como la antítesis de Nina. Su 
imagen desinhibida, sensual y descarada la posicionan como la mejor opción para representar al cisne malvado a ojos del director, y por consiguiente, cancelar la posibilidad de Nina de lograr su tan ansiado objetivo.

Por lo tanto, Lily se convierte, automáticamente, en la imagen de su doppelgänger ${ }^{1}$, establecido a través del rasgo que mejor caracteriza a este fenómeno: la crisis persecutoria que se cierne sobre el sujeto, a través de la firme convicción de que un desconocido individuo -un doble de sí mismoatenta con tomar el control de su vida, a través de la sustitución. Por ello, la parte de Nina que es demandada y no complacida, será proyectada hacia el exterior. En este caso, hacia Lily, siendo el objetivo principal de una serie de fragmentos de carácter alucinatorio.

Debemos atender a uno de las escenas que mejor ilustran este estado de autoscopía, apoyada en la imagen real de Lily.

El momento tiene lugar cuando Nina, afligida por la crueldad que le demuestra Leroy durante los ensayos, acaba por derrumbarse poco después en una de las salas de baile. Sus lamentos son interrumpidos por la llegada de alguien a la sala. Un plano muestra a una figura situada junto al marco de la entrada, oculta por las sombras. La escena viene determinada por el desconcierto que produce esa inquietante presencia, delimitada por el juego de luces y sombras, encargadas de recrear la ilusión óptica.

La irracionalidad que sustenta esta imagen se incrementa con la inserción de un plano del rostro desconcertado de Nina, a la vez que demanda una identificación (“¿quién es?”).

Para incentivar el carácter siniestro que preside en la escena, se acorta la escala de la imagen hasta un plano corto del rostro de esta figura, que permaneciendo aún en la oscuridad, nos vincula automáticamente a la propia Nina sumergida bajo ropas oscuras. Al penetrar el doble en la sala, un haz de luz proveniente del interior de la estancia, incide sobre su rostro, desvelándonos a Lily. Nuevamente, el contraste entre luz-oscuridad es el encargado de otorgar el sentido del episodio sobrenatural que rige la escena.

\footnotetext{
${ }^{1}$ Vocablo de origen alemán (doppel: doble y gänger: andante), empleado con frecuencia en literatura para designar la naturaleza dual de una persona.
} 
El propio Aronofsky señalaría la importancia de este juego de luces en la concepción de la dualidad:

"Lo que me fascinó de la historia era el contraste entre lo luminoso y lo oscuro y cómo las dos fuerzas combaten la una contra la otra” (Aronofsky, 2011: 30).
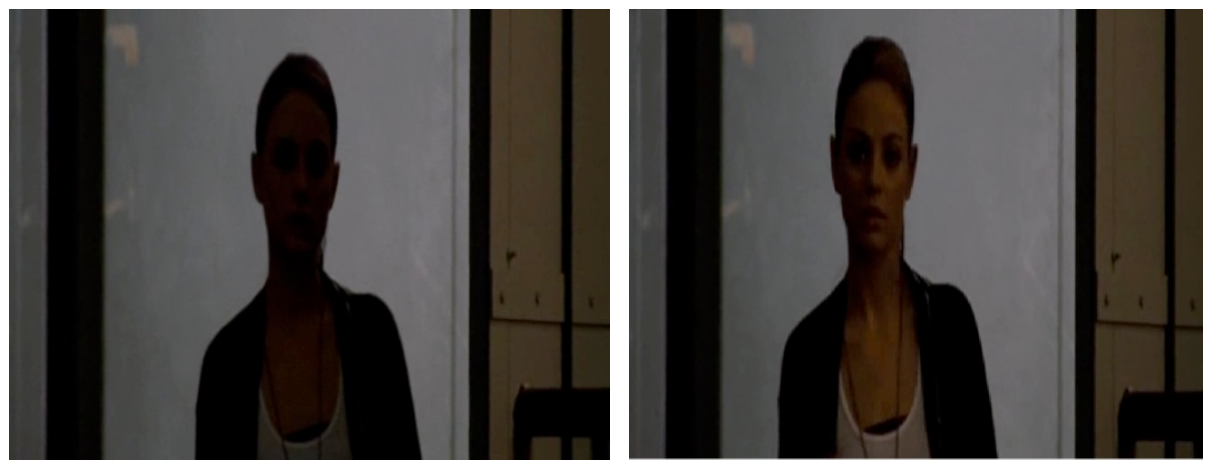

Cisne negro actúa, de este modo, bajo un procedimiento de reiterada distorsión de la percepción. Son una serie de fragmentos destinados a situar al espectador bajo el punto de vista del personaje principal, iniciado a través de la cámara subjetiva. De este modo, se encuentra sometido, junto a la propia protagonista, a un estado de incertidumbre permanente sobre el carácter real o alucinatorio de estas impresiones sensoriales, como tránsito a la locura. En última instancia, Aronofsky aboga por la búsqueda del estímulo emocional característico del género de terror, mediante los efectos sonoros que acompañan a cada una de las múltiples visiones.

Este tipo de fórmula -el impacto como premisa principal para acercar al espectador-, ya fue trabajada con anterioridad por el director en los films $\mathrm{Pi}$, fe en el caos (Pi, Faith in Chaos, 1998) y Réquiem por un sueño (Requiem for a dream, 2000), mediante la presentación de un montaje frenético de imagen y sonido, que invadía la pantalla cada vez que los personajes reincidían en el objeto de su obsesión.

\section{La constitución del doble en el espejo}

"The film is also about doubles and your reflection in a mirror is a double, so mirrors became a really important part of the film" (Aronofsky, 2011). 
Con esta breve cita, Aronofsky subraya el elemento más importante de la narración, en relación a su estrecha vinculación con el doble.

El interés del espejo nace a través de su representación como lugar donde el espacio real es reflejado, y por tanto, duplicado. De modo que, junto a la imagen de Lily, se consolida como el lugar bajo el cual nace y adquiere poder el doble.

Su presencia es fundamental para asistir al progresivo desmoronamiento del personaje principal, de modo que puebla cada uno de los escenarios que envuelven a la protagonista. Cuando la cámara no se encuentra tras Nina, la acción se desarrolla a través de los reflejos de los espejos que constantemente la rodean. Con ello, el espejo ayuda a incrementar la confusión con la que el director trata de sumir al espectador.

El propósito del espejo en la configuración del film, parte de una estrecha vinculación al mundo de la danza. Se trata de un elemento protagonista en la vida de una bailarina, cuya imagen madura en torno al reflejo que de sí misma proyecta el espejo. Nina, por lo tanto, es forzada a enfrentarse a su reflejo con asiduidad.

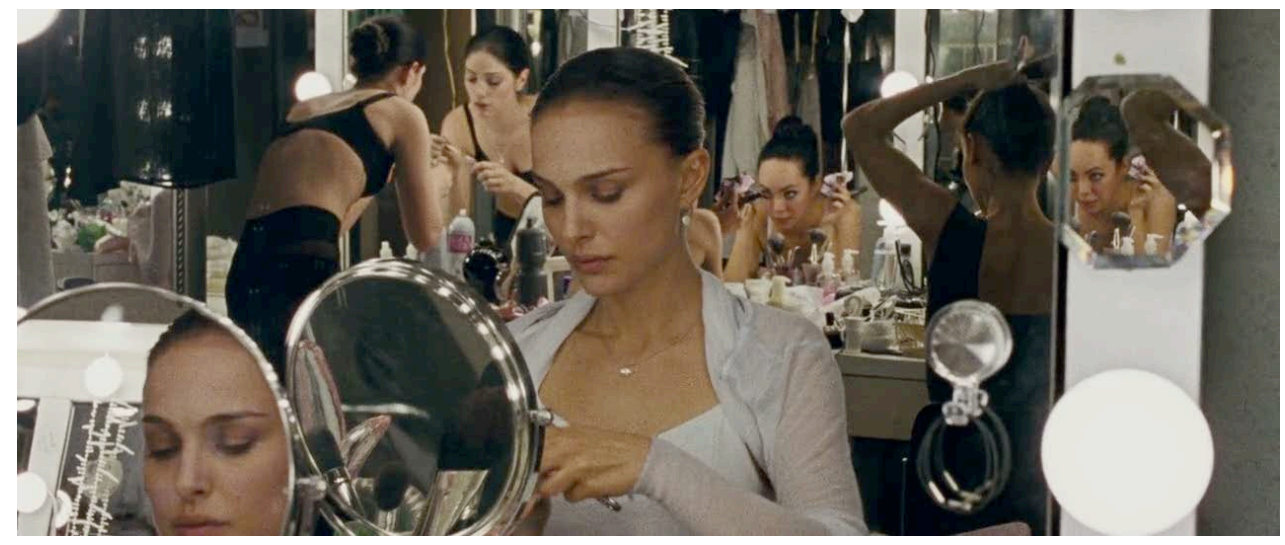

"La función del estadio del espejo se nos revela entonces como un caso particular de la función de la imago, que es establecer, una relación del organismo, con su realidad" (Lacan, 2009: 102).

Tal y como anunciaba el psicoanalista Jacques Lacan en su Teoría del Estadio del Espejo, el valor del individuo se configura a través del reconocimiento de sí mismo -como unidad- a través de la imagen que proyecta el espejo. De este modo, la imposible individualización de Nina y por ello, la pronunciación del doble, responde a su incapacidad de atender a su propia realidad, establecida por una imposible vinculación con esta superficie reflectante. 
A esta relación, Lacan añadía, además, la indispensabilidad de la figura del semejante, la figura materna que afirma el valor de la imagen reflectada, necesaria para acceder al autoconocimiento.

De este modo, la incapacidad de Nina de reconocerse a sí misma, base sobre la que se estructura su psicosis, halla su origen en una relación opresiva con su madre. Un obsesivo vínculo materno-filial, asentado en el odio enmascarado en amor que profesa Erica (Barbara Hershey) hacia su hija. Parte de la actitud que demuestra hacia Nina viene concebida a raíz de su fracaso en el pasado en el ballet, del que, inconscientemente, la cree culpable. Esta dominancia materna mantiene a Nina anclada a un estado de niñez permanente -iniciado en su dormitorio y asentado en el leitmotiv "mi dulce niña"-, en un tiempo muy primario del estadio del espejo, bajo el cual no deja que llegue a tomar conciencia de sí misma, como alguien con identidad, identificable.

En este último aspecto, Nando Salvá observaba que:

"La capacidad de Nina para interpretar a la vez al cisne blanco y al cisne negro depende de su capacidad para dejar de ser una niña y convertirse en un adulto sexual” (Salvá, 2011: 52).

Una capacidad vetada por la intromisión materna. Nina se confronta a una sexualidad que le resulta imposible de apropiarse. Es lo que Lacan denominaba forcluido.

El cine ya ha explotado con anterioridad este tipo de relación devastadora entre madre e hija, con ejemplos como la obra de Brian De Palma, Carrie (1976) o La pianista (20019) de Haneke, donde, en este último caso, la represión sexual a la que se encuentra sometida la protagonista, a través de una dependencia involuntaria al seno materno, la lleva a desahogarse a través de la autoagresión -bajo prácticas de carácter sadomasoquistas-. La satisfacción de una vía insatisfecha que es compartida con la protagonista de Cisne negro.

Nina alivia ese estrago materno a través de los arañazos que se infringe en la espalda (La protagonista de La pianista acudía a una cuchilla de afeitar con la que se realizaba cortes en el sexo). Este tipo de autolesiones, presentes desde el inicio del relato, y producidas como forma de aliviar la tensión acumulada en momentos de angustia, se rige aquí, también, como sustituto onanístico, ante la 
imposibilidad de acceder a su propia sexualidad, coartada por la presencia materna.

Este comportamiento autopunitivo trata de ser erradicado por Erica, a través de aquellos fragmentos en los que acude a las tijeras como forma de evitar la mutilación y, con ello, impedir la satisfacción. Esta relación intrínseca entre el arañazo y el espejo (el único medio para acceder a la espalda), se incrementa mediante la incorporación del doble al discurso.

Zizek destacaría, en su obra apoyada en la figura de Lacan, la relación entre estas dos instancias, atendiendo, nuevamente, al carácter siniestro o unhimliches del doble:

"La imagen del espejo obtiene su carácter unhimliches -el doble es lo mismo que yo, y no obstante, totalmente extraño-; su semejanza acentúa aún más su carácter siniestro. Esta es la razón por la cual la imagen de un doble se transforma con tanta facilidad en su opuesto" (Zizek, 1994: 156).

De este modo, el doble -su identidad rival- emerge a través del espejo. El único elemento que es real respecto a Nina. En este caso, cobra especial importancia el espejo del baño, lugar donde halla su único momento de privacidad y en el que trata de poner límite a la demanda materna.

En este momento, vamos a referirnos a una escena concreta, representativa de esa estrecha relación entre el arañazo y la manifestación del doble, ambas presencias sumidas bajo este elemento.

Nina acude, nuevamente, al espejo del baño para detenerse ante el empeoramiento del arañazo de su espalda, fruto de su progresiva involucración en el doble papel. Atendiendo al mandato materno, Nina toma unas tijeras y comienza a cortarse las uñas con firmeza. La cámara realiza una lenta panorámica desde el rostro de Nina hasta su reflejo, proyectado en el espejo. En ese instante, una extraña presencia parece brotar del cuerpo de la joven y su rostro se torna malévolo, siniestro. Poseída momentáneamente por esta invisible fuerza interna -el doble- se realiza un corte en el dedo con las afiladas cuchillas de acero. Nina sale del trance, instantáneamente, bajo el dolor de la reciente herida infringida. 
Con esta pequeña escena, se produce el primer enfrentamiento entre Nina y su otro yo. El doble que ha tomado poder, con la misión de llevar a cabo la sustitución, terminana por agredir a Nina -autoagredirse-, como parte de esa irracionalidad que sustenta al fenómeno del desdoblamiento de personalidad.
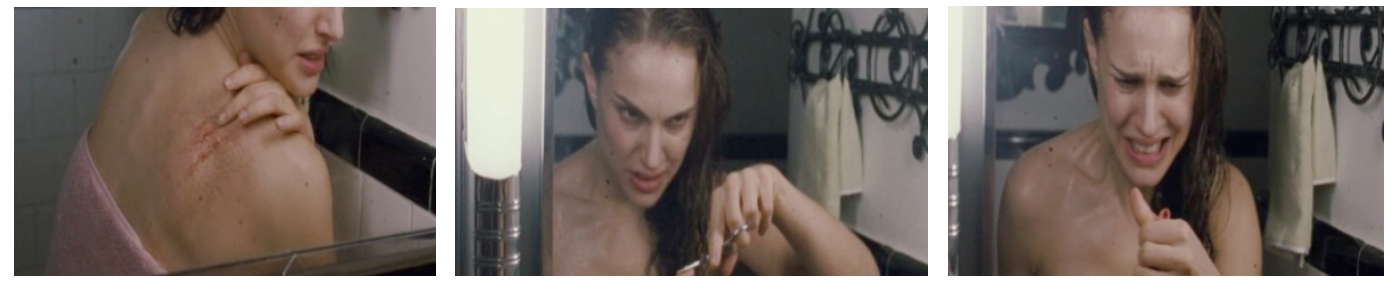

Este fugaz intento de frenar la autocastración -y con ello, permitir el crecimiento del arañazo-, tiene su reflejo en otro aspecto de gran importancia en el desarrollo de la diegésis. La mutación como acompañamiento del doble. A través de una serie de alucinaciones cenestésicas, iniciadas en el sarpullido de su espalda, Nina cree transformarse en el objeto de su obsesión: el cisne negro. Una transformación -análoga a la tratada por Kafka en La metamorfosis (1915)- que tendrá su momento culmen cuando Nina cree ver como una pluma negra es expulsada del interior de la herida, momento que establece la consolidación definitiva del doble.

Este proceso de transformación, atendiendo a la alteración del cuerpo humano, nos remite a la obra de Cronenberg y, concretamente, a La mosca (1986), film en el que un excéntrico científico se ve sumido, tras un experimento fallido, en una monstruosa metamorfosis de hombre a insecto.

En ambas películas, los espejos (y en concreto, el espejo del baño) se encargan de mostrar la minuciosa transformación que va teniendo lugar sobre el cuerpo de los protagonistas. Cada vez que se miran al espejo, asisten, con asombro, a los nuevos cambios que la mutación ha dejado sobre su cuerpo.
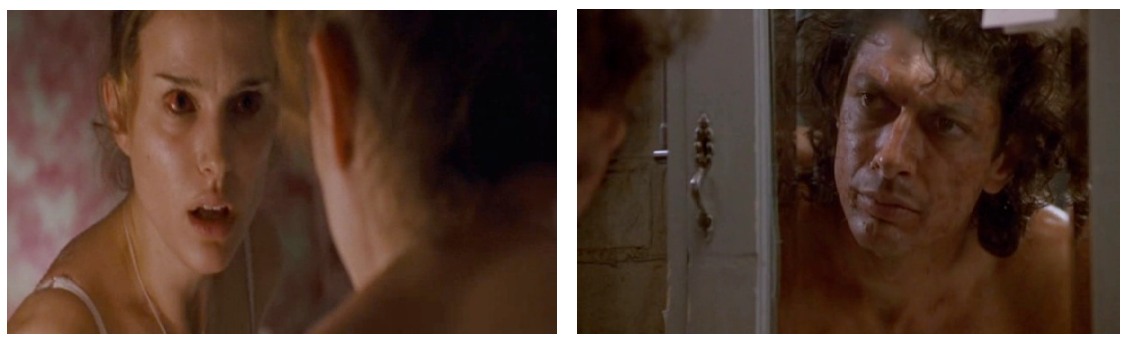

Por otro lado, la inclusión de esta pequeña herida en el relato, nos evoca a las obras anteriores del director, a través de la presentación del estigma, 
perpetuado sobre el cuerpo de los personajes protagonistas. Aronofsky ahonda en las huellas de la autodestrucción en el cuerpo humano, víctima física y psíquica de la determinación inicial de los personajes. El sujeto acaba sumido en la imagen de una pequeña marca o cicatriz, adherida a su piel, como medio que le advierte de las consecuencias de su obsesión. Desde la pequeña ampolla del brazo de Harry, protagonista de Réquiem por un sueño, fruto de las inyecciones de heroína; hasta la cicatriz que deja sobre su pecho la operación de corazón que obliga a Randy (protagonista de El luchador) a abandonar el ring para siempre.

Volviendo a la imagen del doble, inmortalizada por el elemento espejo, podemos detenernos en dos escenas que se suceden casi consecutivamente en el film, y cuya estructuración resulta ser la misma.

En la primera de ellas, Nina se encuentra en el taller de costura de la compañía, aguardando a que la modista le tome las medidas para el vestuario de primera bailarina. El protagonismo recae en los espejos enfrentados, donde Nina, situada en el centro del encuadre, atiende a su figura multiplicada en profundidad. Su vestuario, conformado por ropas oscuras, corrobora, como señalamos con anterioridad, la instauración del desdoblamiento, de la imagen del cisne negro. La escena se caracteriza por el surgimiento de un extraño sonido, que impulsa a Nina a inclinarse hacia su lado derecho, atraída por su procedencia.

Al dejar al descubierto parte del espejo, asistimos, junto a Nina, a la visión del reflejo que parece haber cobrado, momentáneamente, vida propia, mientras se rasca la espalda con vigor. Acto seguido, bajo la desconcertante mirada de Nina, su reflejo se girará hacia ella, consolidando, así, el estado de dominio del doble, perpetuado bajo una ilusión.
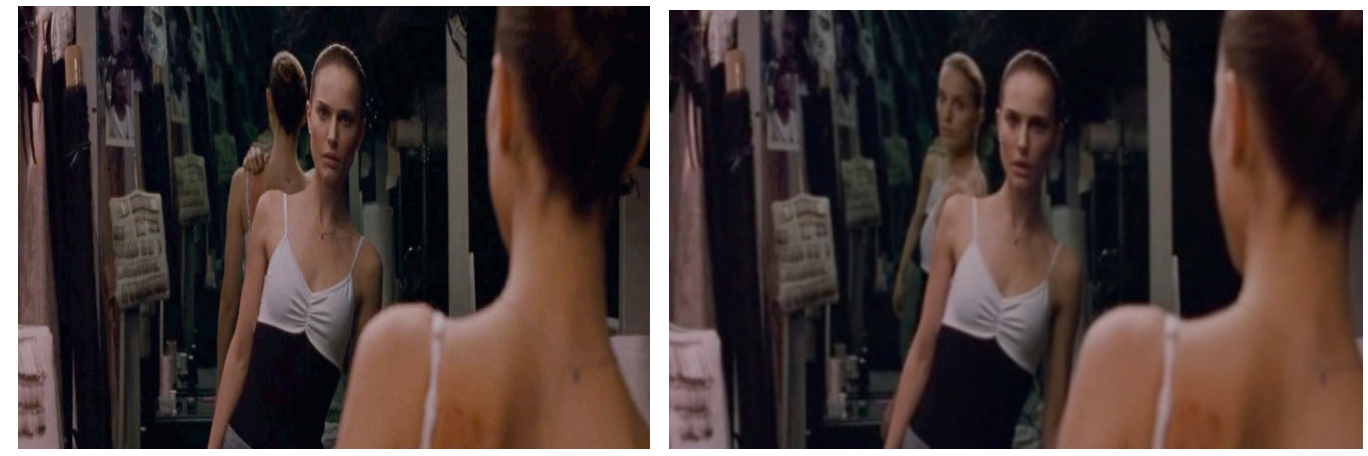
Bajo esta misma visión aterradora, se edifica la segunda de las escenas, que transcurre poco después de este último fragmento. Nina, alarmada por la repentina noticia del ascenso de Lily como su sustituta -en el caso de que ella no pueda bailar durante la obra- ensaya sin descanso la noche anterior al gran estreno. Los espejos vuelven a cubrir todo el encuadre, expectantes a los movimientos que ejecuta la joven bailarina.

Análogamente, en la segunda escena, el reflejo de Nina actúa fuera de sincronía de sus movimientos. El doble, sumergido en el espejo, vuelve a girarse hacia Nina, justo antes de que las luces de la sala se apaguen al unísono, dejándola en completa oscuridad. El lado oscuro, el doble, ha tomado definitivamente el control de su mente.

La configuración de ambas escenas nos evocan a Perfect blue (1997), de Satoshi Kon, obra de interés general para Aronofsky, donde los espejos son, igualmente, los encargados de albergar al doble, fruto del desdoblamiento de personalidad que la protagonista padece.
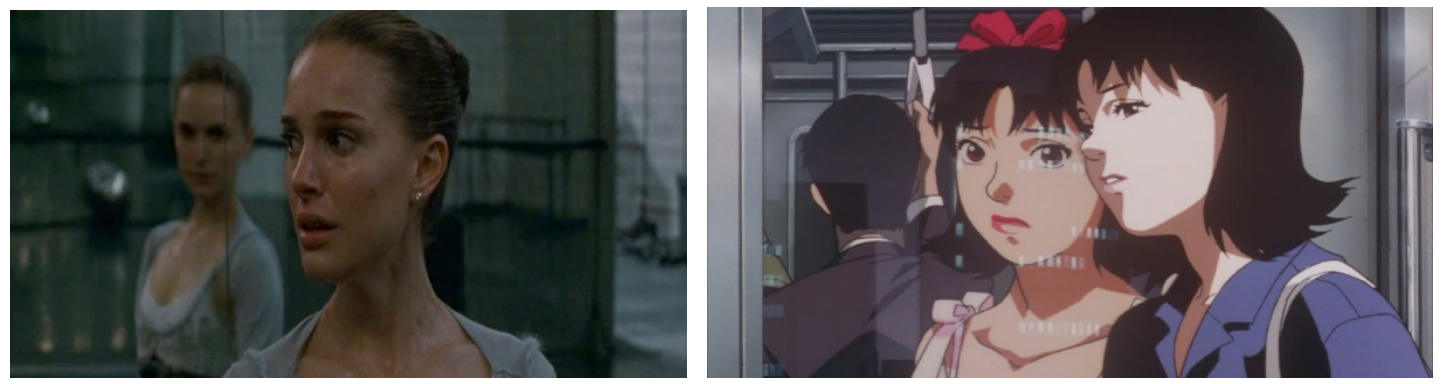

Esta última escena se convierte en el desencadenante final que llevará a Nina a su enfrentamiento ante las dos subjetividades que han regido todo el relato. La primera de ellas, la búsqueda de la perfección, transmitida por su madre y representada bajo la figura de Beth. La segunda, el gozo y el erotismo, promovidos por Leroy -y la figura del cisne negro- y exteriorizados por Lily. Dos estados representantes de los cisnes protagonistas, incapaces de sobrevivir unidos. Su salida, por lo tanto, se reduce a eliminar a estos dos estados contrarios. El "ideal del yo" encarnado por Beth y la perversión instaurada sobre Lily. 


\section{La destrucción de la dualidad}

"Every woman who surrounds Nina is, it seems, both a rival and her double -including suicidal, washed-up former principal dancer Beth (Winona Ryder); the seemingly friendly, sexy rival Lily (Mila Kunis), who wants to take Nina out clubbing; and even her jealous mother Erica (Barbara Hershey), who's terrified of Nina growing up and having a real success that she cannot share" (James, 2011: 34).

Tal y como observaba Nick James, la realidad de Nina se configura en torno a la imagen de múltiples dobles, cuyo presencia en la continuidad de la acción, amenaza, finalmente, con romper la integridad de Nina. De modo que, al final del relato, se ve sumida por una coexistencia imposible. En este momento, Nina acude a la eliminación, o lo que es lo mismo, a la autodestrucción, como vía para hallar su liberación. Se produce la muerte simbólica de estos dos estados o subjetividades, mediante dos nuevos fragmentos de carácter alucinatorio.

A continuación, vamos a referirnos a la construcción de estas dos escenas.

La primera de ellas tiene lugar cuando Nina acude al hospital a buscar amparo en Beth, la ex primera bailarina, convaleciente tras el desafortunado accidente que la deja invalida para siempre. Su llegada desconcierta a la enferma que increpa a Nina cuando ésta deposita sobre su mesa aquellos objetos que, clandestinamente, robó de su camerino tras su expulsión. Nina, desesperada, se refugia en el delirio persecutorio instaurado sobre Lily ("ella intenta ocupar mi lugar”), mientras reincide en el objeto de su obsesión (“solo intentaba ser tan perfecta como tú”).

De este modo, el “ideal del yo", encarnado por Beth, es destruido ante la idea de convertirse ahora en el nuevo sujeto reemplazado. De pronto, el sentido de la acción es interrumpido cuando Beth toma entre sus manos la lima de uñas de la que Nina se había apropiado anteriormente y, sin dudarlo, comienza a apuñalarse el rostro con brutalidad mientras vocifera: "no soy nada”.

La automutilación vuelve a presidir el relato. La lima como símbolo de la castración a la que se venía sometiendo Nina a través del yugo materno y las tijeras. En este caso, la lima -objeto de similar utilidad- es utilizada ahora para 
destruir el objeto de perfección y belleza, atacando, así, a la figura a la que se vinculaba (Beth).

Cuando Nina trata, en última instancia, de contener la destrucción, arrebatándole el arma a la ex primera bailarina, su rostro desaparece para reflejar al del doble, que continúa acuchillándose el rostro, mientras Nina huye aterrada de la habitación.
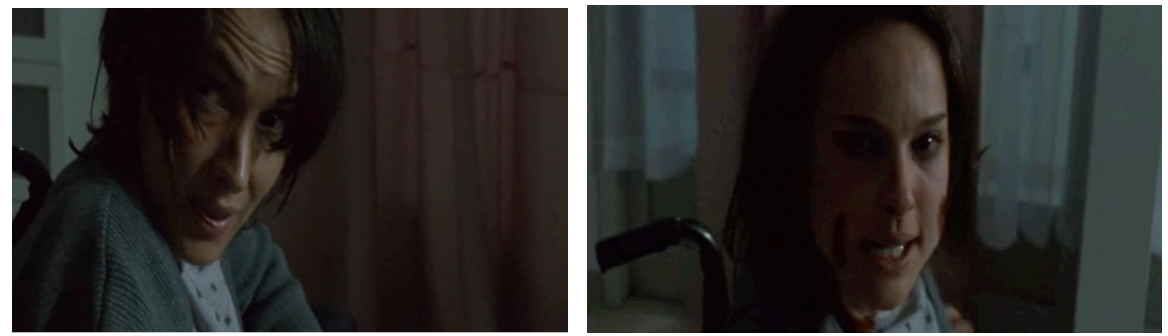

Aronofsky ataca nuevamente el sentido del relato, emplazando un universo que oscila entre la realidad-irrealidad. El espectador se sitúa en la mente trastornada de la joven bailarina, sin conocer si el fragmento visionado se trata de una automutilación real -de naturaleza suicida- de Beth, o un nuevo episodio alucinatorio de la protagonista, que se incrementa cuando al entrar en el ascensor del hospital, huyendo de la siniestra aparición, descubre con horror la lima de uñas impregnada en sangre en su mano.

Una vez se produce la desvinculación del objeto de perfección, Nina queda a merced de la segunda subjetividad, el gozo representado por Lily -la imagen del cisne negro- en un semejante proceso de destrucción.

La escena tiene lugar el día del estreno de la famosa obra de ballet, donde Nina debuta como primera bailarina. Tras finalizar el segundo acto, Nina, ataviada con el disfraz de la reina cisne, acude a su camerino para reemplazar su vestuario por el de su gemela, el cisne negro. Allí encuentra a Lily, sentada frente a su tocador, portando sus ropas y tratando de provocar a Nina con la actitud del doble: “¿Qué te parece si yo bailo el cisne negro por ti?”.

El espejo, elemento del que nos ocupamos con anterioridad, símbolo del desdoblamiento, vuelve a protagonizar la escena. La cámara, situada tras Lily, realiza una pequeña panorámica a medida que ésta se gira hacia Nina, produciéndose, nuevamente, la sustitución de su rostro por el de la propia Nina. Se trata de la expulsión del doble desde el espejo. 
Las palabras de Lily corroboran lo enunciado con anterioridad por Leroy ("la única que se interpone en tu camino eres tú”).
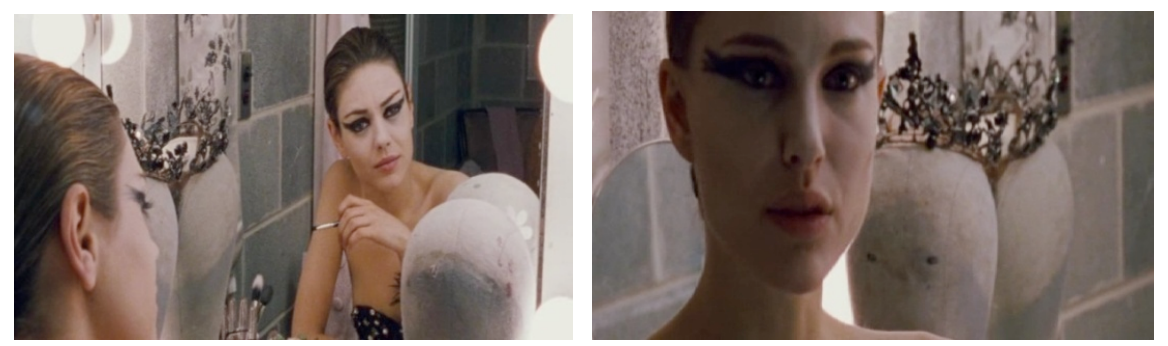

Tras esta sentencia, se produce el enfrentamiento final que guía la acción, cuando Nina, movida por un sentimiento de miedo e ira, se abalanza contra el doble, empujándola con violencia contra el espejo del camerino, que estalla en multitud de fragmentos. La encarnecida lucha entre las dos dualidades -el cisne blanco y el cisne negro- enfrentados bajo los cristales rotos del espejo que se regía como único elemento que los separaba.

La inverosimilitud preside en un enfrentamiento definido por la lucha del individuo contra su propia persona. Un procedimiento que nos evoca a la obra de David Fincher, El club de la lucha (1999), donde el personaje principal -un individuo que sufre un desdoblamiento de personalidad- se encaraba, finalmente, a la partición oscura de su mente, a través de un violento encuentro consigo mismo.

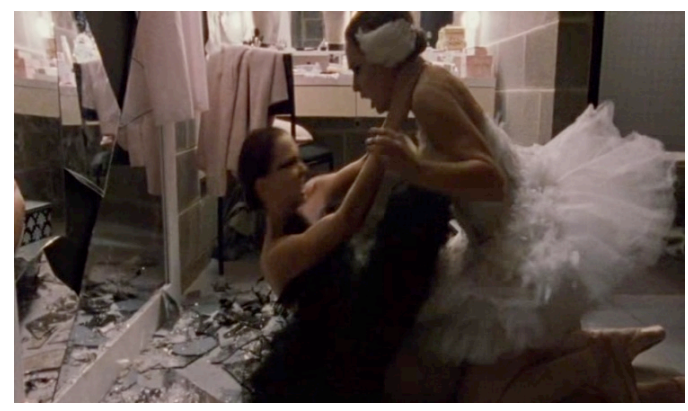

Se escenifica el acto de liberación a través de la pelea del individuo contra su propia imagen, ya iniciado con el enfrentamiento ante Beth. De este modo, bajo el mensaje "es mi turno", la dualidad es, inevitablemente, cancelada. Nina da muerte al doble al apuñalarle el vientre con uno de los fragmentos del espejo. El trozo de espejo del que, hasta este momento, se servía la imagen del doble, actúa ahora como el arma que lo destruye. Un apuñalamiento que actúa, además, como símbolo de la conclusión del acto sexual, perpetrado con el trozo de cristal por el cual emana la sangre que destruye finalmente a su antagónico. De modo 
que, tras creer haber dado muerte a su rival, a su doble, es capaz de sumergirse en la piel del cisne negro -de confrontar la pulsión sexual- y ejecutar su presentación en la obra.

Sin embargo, su nublado raciocinio le impide comprender las consecuencias del acto cometido, ya que al apuñalar al doble, no ha hecho si no apuñalarse a sí misma. De este modo, se desata el acto de suicidio inconsciente, que culmina en el escenario, a través de la representación del último acto de la obra -la muerte de la reina cisne- que concluye, tras el apoteósico final, con su propia muerte. La doble muerte bajo la que Nina consigue conciliar las dos dualidades. El cisne blanco y el cisne negro. Al igual que en la obra de Tchaikovsky, solo en su propia muerte consigue hallar la libertad.

De este modo, Aronofsky expresa la visión de la propia destrucción, ya apuntada en sus largometrajes anteriores, como vehículo por el que los personajes principales, atados a sus obsesiones, acceden al autoconocimiento. El sujeto protagonista está sujeto, nuevamente, a una imposible redención. En Cisne negro, al enfrentarse a las consecuencias de su obsesión, Nina, consigue a su vez, consumarla: "Estuve perfecta”.

\section{Referencias bibliográficas}

ARONOFSKY, Darren (2011). "In-Depyh Interview with Darren Aronofsky for Black Swan”. En Flicks and Bits: http://www.flicksandbits.com/2011/01/17/in-depth-interview-withdarren-aronofsky-for-black-swan-starring-natalie-portman/6635/.

[Consultada 10/08/2011].

DOSTOYEVSKI, Fiodor (1985). El doble. Madrid: Alianza.

FREUD, Sigmund (1992). "El yo y el ello”. Obras completas, Vol. XIX. Buenos Aires: Amorrortu.

FREUD, Sigmud (1992). "Lo ominoso". Obras completas, Vol. XVII. Buenos Aires: Amorrortu.

JAMES, Nick (2011). "Dancer in the dark". En Sight \& Sound, febrero, pp. 3336. 
KAFKA, Franz (2011). La metamorfosis. Madrid: Alianza.

LACAN, Jacques (2009). "El estadio del espejo como formador de la función del yo [Je] tal y como se nos revela en la experiencia psicoanalítica”. Escritos, Vol. 1. México: Siglo XXI.

LACAN, Jacques (2000). "Introducción a la cuestión de la psicosis”. Seminario 3, La psicosis. Paidós.

LERMAN, Gabriel (2001). "Entrevista. Darren Aronofsky”. En Dirigido por, enero, pp. 28-31.

PIERCE, Michael. "Directors of the year. Darren Aronofsky”. En International Film Guide: http://www.internationalfilmguide.com/ [Consultada 04/07/2011].

POSECK VERA, Beatriz (2006). “iEl asesino era yo! O el trastorno de identidad disociativo en el cine”. En Rev Med Cine2, pp. 125-132.

http://campus.usal.es/ revistamedicinacine/Volumen 2 1/n4/esp 4 pdf/transtdisocia.pdf [Consultada 27/07/2011].

RAMÍREZ GUZMÁN, Fernando (2011). "El cine de la obsesión: Aronofsky”. En Siglo nuevo (El siglo de Torreón), año 6, nº 133, julio, pp. 26-29.

SALVÁ, Nando (2011). “Cisne negro”. En Cinemanía, febrero, p. 52.

ZIZEK, Slavoj (1994). iGoza tu síntoma! Jacques Lacan dentro y fuera de Hollywood. Buenos Aires: Nueva visión. 